\section{Covid Warriors in India: Battling Denial Stigma and Discrimination}

\section{Dr Venkat Rao Pulla ${ }^{\dagger}$}

The year 2020, with the COVID 19 pandemic on, there was a subdued Onam celebration in the Kerala state of India The Chief Minister called social distancing as a 'social vaccine' until the real vaccine is germinated (The Hindu, 2020). Eradication seems an illusion. Amidst indiscipline and scant regards to physical distancing norms, many countries are remirroring death tolls. Ironically freedom that was put away in the closet for nearly eight months has been replaced by chaos, mass movement ensconcing the second surge of the pandemic. I thought previously that our political leaders learnt a few lessons through the pandemic. Alas, the fear of death seems to be still lurking (Pulla, 2020). We are aware of inevitable mortality but to invite death to our doorsteps and into our homes prematurely -1 do not seem to understand, why?

Authors Robert Firestone and Joyce Catlett in their book, Beyond Death Anxiety (2009), elude to how the fear of death influences a core paranoia in people when they face destructive forces beyond their prowess and capability to control and become aware that the forces would eventually possess them. While fear may not seem to be a deterrent, accompanied anxiety, sadness, and uncertainty about the future of humanity seem to be getting us all down.

Several reported cases of denial, stigma and discrimination against the health care workers and all other professionals seem to have surfaced in India. The UK, the USA, and Australia

\footnotetext{
${ }^{+}$Editor in Chief (Joint), Space and Culture, India; Foundation Professor, Brisbane Institute of StrengthsBased Practice, and Adjunct Senior Research Fellow, Institute for Land Water and Society, Charles Sturt University, Albury, Wodonga, NSW, 2640, Australia; Sessional Academic, Social Work Charles Darwin
} (C) 2020 Pulla. This is an Open Access article distributed under the terms of the Creative Commons Attribution License (http://creativecommons.org/licenses/by/2.0), which permits unrestricted use, distribution, and reproduction in any medium, provided the original work is properly cited. do not seem to make a difference. The following narrative from the UK reinforces this:

My name is Niaz. I am an Anaesthesiologist, a COVID-19 front-line worker and a COVID-19 survivor as well. I am presently recuperating from a second cardiac surgery. Yes, I have been stigmatised, beaten, punched, threatened by thugs, because of my COVID-19 status. I have complained to the police who are investigating the incidents. It is just because of my vulnerability. As front-line workers, even with best of precautions, we are still gullible, and in a susceptible situation. For, all our working hours, which is now equivalent to waking hours, we are with COVID-19 patients in critical care

Dr. M. Niaz Ahmed, Department of Anaesthesia, Ingham wing, South Tyneside Foundation Trust Hospital, Newcastle, United Kingdom (2020).

It is imperative that in order to protect the lives of the multitudes, we first must protect the lives of their protectors. Many of them have been shunned due to the mistaken fear of getting infected by those front-line "COVID warriors". More often than not, instances have included overt and covert acts of physical and verbal violence, several acts of commission and omission, including health workers being evicted from their own homes, which they as occupants are fully authorised to use (Gopal, 2020). The ostracisation seems to be scaling new heights resulting in total avoidance by the society at large. It is more seeming now to all, that stigma and stigmatisation essentially involve a narrative of social relations: an attribute that shames

University, NT, Australia, Sessional Academic, Human Services, James Cook University, Townsville, Australia; Inaugural Fellow, Australian College of Researcher \& Life Member, Australian Institute of International Affairs, Australia, Email: dr.venkat.pulla@gmail.com 
bearers at one spatio-temporal juncture can pass them by at another (Scambler,2016).

This editorial is inspired by the several personal communiques from the Network of the COVID Action Community India, of which I am a member. This is a subgroup of the Peer Consult groups (PC-Groups) set by professionals that work for WHO and others in the development sectors. In one of the dispatches, a colleague who wished to remain anonymous wrote as follows:

'Stigma and Discrimination felt by me as COVID19 Survivor are:

- The doctor kept a distance from me, while giving me factual oral updates about my clinical status when I was admitted to a COVID-19 Hospital.

- Consequently, after discharge from the hospital, when my neighbourhood was declared a quarantine zone, every passer-by is going on the right side or farther side than on the left side of the road, to keep as far away from my house.

- All neighbours and relatives have stopped visiting my house after I returned from the hospital.

- However, during my stay in the hospital, I saw that many relatives are taking care of their COVID-19 kith and kin, and they were in close contact with the patients 24X7; and they were not discriminating their own family members.

- This was an eye-opener for me, and I appreciate those relatives who care for their COVID-19 loved ones. Anonymous (Peerconsult.network,2020).

Furthermore, it is shocking that denial, stigma and discrimination seem to have seeped into our communities and that people seem to be committing suicide when they come to know they have tested positive for COVID-19. A recent study presented 69 COVID-19 suicide cases aged between 19 to 65 years out of which 63 were males (Dsouza et al., 2020).

The causalities identified with the cause of fear of COVID-19 infection ( $n=21)$, financial crisis $(n=19)$, and the rest sprang from the loneliness, social boycott and pressure to be quarantined, or were COVID-19 positive. The other set of reasons were COVID-19 work-related stress and their inability to come back home due to lockdowns, and even unavailability of alcohol etc. (Dsouza et al., 2020). Dr Rafique, CardioVascular Health Officer (CVHO), World Health Organisation (WHO), Wayanad, Kerala, writes that people are afraid of going to a hospital for fear of getting infected with COVID-19. When he asked his non-communicable diseases (NCD) patients why they are not accessing the hospitals for their ailments, they replied that they prefer to die of NCD complications which may arise a decade or two later than to die in a week or two by contracting COVID-19 (Rafique, 2020).

COVID 19 has also become a business opportunity for the unscrupulous. It has been reported that some pathological testing services seem to be making the most in these pandemic times, by first giving a false-positive certificate, so that all other family members of that socalled index case will return for testing (The Hindu, 2020). Testing laboratories are few and far between; many people do not have medical insurance. To compound hospitals are detaining the tragedy bodies of the deceased over nonpayment of inflated bills (Rafique,2020). Where do you begin to describe the deviousness in these challenging times?

The stigma is directed towards those recovered; those undergoing treatment; those presumed to be affected or have a member of their family exposed to COVID19. The brunt of social stigma is directed to frontline workers, medical practitioners, nurses, police personnel, etc. and in some instances forced to leave the neighbourhood and denied access to their houses and the families have been threatened (Bhattacharya et al., 2020).

The way mental health practitioners are labelled as 'paagolon ka doctor' (doctor for the mad person), the frontline workers who are tending to those affected by COVID-19 are being stereotyped against (Bhattacharya et al., 2020 p. 383). 
The newspapers in India, many of them carried tales about the interstate migrant groups that returned to their villages in Jharkhand, Uttar Pradesh and Odisha from industrial towns and cities in India over issues relating to transport food and ill-treatment meted out to them in transit. The story runs further that they too, were not spared from stigma and discrimination. They were treated as suspects that carried the virus. At some places, they have been cast off even after completing the mandatory 14 days' quarantine (Kumar \& Mohanty, 2020).

The villagers were angry because I had ventured out of the primary school, where I was quarantined, to relieve myself," Shekhar said: Okani ke corona ke dar rahal na ta mariye det sa (The villagers were scared of contacting the coronavirus, so they didn't touch me. Otherwise, I would have been killed that day), he said, claiming that he had no symptoms of Covid (Kumar \& Mohanty, 2020).

I am aware that education is disrupted, and loss of incomes and increased poverty is spreading across every nation as a result of unemployment. However, further violence and threats to the safety and well-being of care workers is very important. It appears clear that we might need an approach that contains legally tenable sanctions in society that would consider hateful acts, discrimination and/or harassment of all people that are suffering in the pandemic including workers who are mitigating and serving the populations. A human rights framework is imperative at all times.

\section{References}

Ahmed, N. (2020, 15 September). Dr. Niaz, recounts his DSD experiences, both as frontline worker and COVID-19 survivor.

Communication to https://peerconsult.network/g/CovidActionin/topic/76703574\#71

Bhattacharya, P., Banerjee, D., \& Rao, T. S. (2020). The "Untold" Side of COVID-19: Social Stigma and Its Consequences in India. Indian
Journal of Psychological Medicine, 42(4), 382386.

Dsouza, D., Quadros, S., Hyderabadwala, Z. J., \& Mamun, M. A. (2020). Aggregated COVID-19 suicide incidences in India: Fear of COVID-19 infection is the prominent causative factor. Psychiatry Research, 113145

Firestone, R.W. \& Catlett, J. (2009). Beyond Death Anxiety: Achieving Life-affirming Death Awareness. 408 pages (paperback) Springer, New York, https://www.springerpub.com/beyond-deathanxiety-9780826105516.html

Gopal, R. (2020) Strategies for addressing Denial, Stigma and Discrimination (DSD) in COVID-19, Moderator, Peer Consult, https://peerconsult.network/g/CovidActionin/message/52

Kumar, C.\& Mohanty, D. (2020, 11May). The Hindustan Times, Migrant workers battle stigma, bias back home, https://www.hindustantimes.com/indianews/migrant-workers-battle-stigma-bias-backhome/story-OuuRSEZfoickVOrPU2agGL.html

Peerconsult.network (2020), This post is on behalf of one who prefers to be anonymous due to the DSD issues in COVID-19. https://peerconsult.network/g/CovidActionin/topic/76703574\#71

Pulla, V. (2020, forthcoming COVID 19 special edition). As humanity copes through a pandemic- Editorial Essay, International Journal of Innovation, Creativity and Change.

Rafique, M, (2020) Strategies for addressing Denial, Stigma and Discrimination (DSD) in COVID-19, Moderator, Peer Consult, https://peerconsult.network/g/CovidActionin/message/52

Scambler, G. (2009). Health-related stigma. Sociology of health \& illness, 31(3), 441455.

Staff Reporter (2020, 04 July). Discrepancies in corona tests and data from private labs. The Hindu. 
https://www.thehindu.com/news/national/tela ngana/discrepancies-in-corona-tests-and-datafrom-private-labs/article31990664.ece

The Hindu (2020, 03 September). COVID-19 Onam effect after two weeks: CM,

https://www.thehindu.com/news/national/ker ala/covid-19-onam-effect-after-two-weeks$\mathrm{cm} /$ article32516504.ece

\section{About the Author}

Professor Venkat Rao Pulla, latest book, Discrimination, Challenge and Response: of People of North East India has been published in September 2020 by Palgrave Macmillan. This is an edited book with Dr Rituparna Bhattacharyya and Professor Sanjai Bhatt. A review of this book is included in the current issue of the Journal. Professor Pulla serves on the editorial board of the International Journal of Innovation, Creativity and Change. He is an Inaugural Fellow, Australian College of Researchers \& Life Member, Australian Institute of International Affairs and the Foundation Professor, Brisbane Institute of Strengths-Based Practice. His linked in can be accessed at:

https://www.linkedin.com/in/venkat-pullaa196998/. 